\author{
References \\ Burrell, G., and G. Morgan. 1979. Sociologi- \\ cal Paradigms and Organisational Anal- \\ ysis. Portsmouth, NH: Heinemann. \\ Fiske, J., and J. Hartley. 1978. Reading \\ Television. London: Methuen and Com- \\ pany. \\ Hy, R. J. and L. Hughes. 1988. Activating \\ public administration students in a statis- \\ tics course: A team-teaching approach. \\ Teaching Political Science, 2:60-64. \\ Johnson, J., and R. Joslyn. 1991. Political \\ Science Research Methods. Washington: \\ Congressional Quarterly Press.
}

Michalko, M. 1991. Thinkertoys: $A$ Handbook of Business Creativity for the 90s. Berkeley, CA: Ten Speed Press.

Reinharz, Shulamit. 1979. On Becoming a Social Scientist: From Survey Research and Participant Observation to Experiential Analysis. New Brunswick, NJ: Transaction Publishers.

Schein, Edgar. 1969. Process Consultation: Its Role in Organization Development. Reading, MA: Addison-Wesley Publishing Company.

Yin, Robert K. 1988. Case Study Research Design and Methods (revised edition). Newbury Park: Sage Publications.

\begin{abstract}
About the Author
Larry Hubbell is an assistant professor in the political science department of the University of Wyoming. He primarily teaches and conducts research in the areas of organization theory, public personnel management, and organization development.
\end{abstract}

Note: A course syllabus is available by contacting the author at the Department of Political Science, University of Wyoming, Laramie, WY 82071.

\title{
Traditional Versus Technology-Aided Instruction: The Effects of Visual Stimulus in the Classroom*
}

\author{
Donald L. Jordan, United States Air Force Academy \\ Peter M. Sanchez, Loyola University Chicago
}

The extravagant claims of the vendors of multimedia applications have raised the expectations of teachers who are searching for ways to improve their classroom performance. These teachers frequently see multimedia resources as a natural way to present material to a generation of students weaned on hours of television.

Educators also assume that the students of today will learn and retain more through visual or computerized instruction, or that students, at a minimum, will enjoy their educational experience more if it is enhanced by visual stimulation. For example, it is logical to think that students who are learning about congressional politics will gain a better understanding if they can see the U.S. Congress at work.

One major pitfall in this technological approach, however, is the enormous cost of many multimedia applications, especially in times of tight budgetary constraints. Perhaps more importantly, some evidence suggests that the use of technology and other innovations in the classroom does not significantly improve student performance (Janda 1992; Spencer 1991; and Summers 1990-1991). Before educational institutions spend signif- cant portions of their budgets on multimedia technology, they should consider the utility of such expenditures.

\section{The Experiment: A Brief Description}

We undertook this small, controlled experiment to see whether the use of short video clips in the classroom would enhance our students' ability to learn and retain information about some basic concepts in American government. We divided 117 freshmen into six sections in an introductory American government class at the United States Air Force Academy. As one might expect at a military academy, this population was fairly homogeneous. ${ }^{1}$

The students were placed into specific sections by an alphabetic process; the first student was placed into section one, the second into section two, and so on. Each instructor had three sections of approximately 19 students. For each instructor, two sections were designated "treatment" or "video" sections $-a$ total of four sections and 79 students. Each instructor also had a section labeled "traditional," which would serve as control groups, with a total of 38 students.

Through this relatively random process, we were fairly confident that the sections began with no significant differences in aptitude. This assumption was also supported by the results of an American government pretest administered to all incoming students the previous summer. The independent t-test results in Table 1 demonstrate that the pretest performance of the two groups-c"traditional" and "video" -was indistinguishable.

In the video sections, many of the concepts in the course were presented through video clips. ${ }^{2}$ The two instructors jointly planned each lesson to ensure that all video sections received the same video clips. These clips were then shown in all of the video sections. For example, when discussing judicial restraint, we showed a short video clip of Judge Robert Bork discussing this concept during the Senate Judiciary Committee's hearings to consider his ratification for the Supreme Court.

In the other sections we used a traditional method of classroom instruction to provide a control for the experiment. In these sections almost all teaching was accom- 


TABLE 1
Pretest
\begin{tabular}{lccc}
\multicolumn{1}{c}{ Group } & $\mathrm{N}$ & & \\
\hline traditional & 38 & Mean Score & St Dev \\
video & 76 & $68.6 \%$ & 12.5 \\
pooled variance & $\mathrm{t}=.369$ & 67.6 & 13.1 \\
\hline
\end{tabular}

TABLE 2

Exam \#1-Non-Video Questions (27 each)

\begin{tabular}{lccc}
\hline \multicolumn{1}{c}{ Group } & $\mathrm{N}$ & Mean Score & St Dev \\
\hline traditional & 39 & $77.1 \%$ & 9.0 \\
video & 77 & 77.1 & 9.3 \\
pooled variance & $\mathrm{t}=.000$ & $\mathrm{DF}=114$ & Prob $=1.00$ \\
\hline
\end{tabular}

plished through lectures and discussions. When films were used, they lasted the entire class period, or close to the entire period. In every case, the concepts highlighted in the video sections by the use of videos, were discussed in detail more traditionally in the control sections.

To determine the effects of the visual stimulus in the video sections, multiple-choice questions addressing the concepts augmented by video were constructed and incorporated into three examinations throughout the course. Thus, we tagged certain questions in the exams as "video" questions. Our working assumption/hypothesis was that if the video clips helped the students to better understand concepts, then they should on average score better on these questions than the students in the traditional sections. We expected that the video sections would have a higher mean than the traditional sections on all examinations, especially on those questions that we categorized as video questions. ${ }^{3}$

\section{Results of the Experiment}

The results on the first examination were striking. Table 2 shows that there was no difference in performance on test questions that had no video augmentation. to the experiment since they suggest that all students performed at the same level on questions that were not aided with video clips. If
These results are very important students in the video sections had done poorly on the nonvideo questions, then we would have to conclude that an emphasis on concepts supported by video clips hindered student learning on nonvideo-aided concepts. Or, we would conclude that the instructors placed so much emphasis on the video concepts that they short-changed the nonvideo concepts. 4

At this point, though, the most exciting result was the difference in performance on those questions that tested concepts expanded upon with video. Table 3 demonstrates that the students in the video sections on average scored 9.3 percentage points higher than the students in the two traditional sections, with a significance level of $99.8 \%$. Despite our determination to remain objective and even skeptical about the potential effectiveness of the use of video, the statistically significant difference of almost ten percentage points agitated both researchers.

Our initial enthusiasm was quickly sobered by the results of the second exam. Again, there was no significant difference in performance on nonvideo questions. Unfortunately, there was also no difference in performance on those questions testing concepts augmented by video clips. Table 4 indicates that on the second exam the video students scored only .5 percentage points higher than the traditional students on the video questions.

There are many potential explanations for this finding. Again, perhaps we subconsciously overcompensated in the nonvideo sections by trying too hard to insure video concepts were adequately covered. Perhaps the novelty of the use of videos simply wore off, and the students turned off when the laser disc player came on. We wondered if perhaps the students had caught wind of the experiment and the nonvideo sections were trying extra hard to keep up.

On the final exam we repeated the 15 video questions. Here, once again, we found that the students exposed to video performed better on these questions. Table 5 reflects that the video students scored 3.1 percentage points higher than the traditional students on the video questions in the final exam. These results were nearly significant at the $95 \%$ level, with a probability of .0575 . However, the results were probably largely influenced by the striking results on the first exami-

\section{TABLE 3}

Exam \#1-Video Questions (6 each)

\begin{tabular}{|c|c|c|c|}
\hline Group & $\mathrm{N}$ & Mean Score & St Dev \\
\hline $\begin{array}{l}\text { traditional } \\
\text { video } \\
\text { pooled variance }\end{array}$ & $\begin{array}{l}39 \\
77 \\
t=2.91\end{array}$ & \begin{tabular}{c}
\multicolumn{1}{c}{$84.4 \%$} \\
93.7 \\
$D F=\quad 114$
\end{tabular} & $\begin{array}{c}18.7 \\
14.8 \\
\text { Prob }=.002\end{array}$ \\
\hline
\end{tabular}

\section{TABLE 4}

Exam \#2-Video Questions (7 each)

\begin{tabular}{|c|c|c|c|}
\hline Group & $\mathrm{N}$ & Mean Score & St Dev \\
\hline $\begin{array}{l}\text { traditional } \\
\text { video } \\
\text { pooled variance }\end{array}$ & $\begin{array}{l}37 \\
72 \\
t=.146\end{array}$ & $\begin{array}{l}85.2 \% \\
85.7 \\
D F=\quad 107\end{array}$ & $\begin{array}{c}18.3 \\
16.7 \\
\text { Prob }=.442\end{array}$ \\
\hline
\end{tabular}




\begin{tabular}{|c|c|c|c|}
\hline \multicolumn{4}{|c|}{$\begin{array}{l}\text { TABLE } 5 \\
\text { Final Exam Video Questions (13 each) }\end{array}$} \\
\hline Group & $\mathrm{N}$ & Mean Score & St Dev \\
\hline $\begin{array}{l}\text { traditional } \\
\text { video } \\
\text { pooled variance }\end{array}$ & $\begin{array}{l}39 \\
78 \\
t=1.59\end{array}$ & $\begin{array}{l}89.2 \% \\
92.3 \\
\mathrm{DF}= \\
=\end{array}$ & $\begin{array}{c}8.5 \\
10.0 \\
\text { Prob }=.0575\end{array}$ \\
\hline
\end{tabular}

\section{TABLE 6}

Final Course Grade Average

\begin{tabular}{|c|c|c|c|}
\hline Group & $\mathrm{N}$ & Mean Score & St Dev \\
\hline $\begin{array}{l}\text { traditional } \\
\text { video } \\
\text { pooled variance }\end{array}$ & $\begin{array}{l}39 \\
78 \\
t=.754\end{array}$ & $\begin{array}{c}81.7 \% \\
82.5 \\
\mathrm{DF}=\quad 115\end{array}$ & $\begin{array}{c}5.1 \\
5.4 \\
\text { Prob }=.2265\end{array}$ \\
\hline
\end{tabular}

nation. Again there was no significant difference in performance on nonvideo questions.

\section{Discussion}

Despite our initial excitement and optimism, our findings indicate that, in this experiment, exposure to video in the classroom may have had only a minor impact on students' abilities to grasp and retain material. Students in the video sections did do a bit better on average throughout the entire course, though only statistically significant on the first examination. Table 6 shows that the video students performed better than the traditional students in the course by .8 percentage points (significance of $77.4 \%) .5$ The video students also scored higher on graded written work, averaging $85.8 \%$ as compared to $84.6 \%$ for the control group. But these results were not significant even at the $95 \%$ level.

Strangely, there was no indication that the students who were exposed to video clips enjoyed the course more than the others. As a matter of fact, the traditional students rated the course slightly higher than the video students! In an end-of-course critique question, which asked the students to compare their level of enjoyment of this course with others at the Academy on a scale from 1-9 (nine being the best), the video sections gave the course a 7.94 rating, while the traditional sections gave the course a 7.95 rating (not significant at the $95 \%$ level).
There are many possible explanations for our results. First, contrary to the conventional wisdom, video augmentation may not be helpful in enhancing student understanding. If this is the case, it may be more advisable for educational institutions to spend their resources augmenting the effectiveness of teachers rather than purchasing high technology software and hardware.

Second, the videos used in this experiment may not have been adequate in explaining the concepts they were meant to explain. This conclusion in our opinion must be seriously considered, since we believe that most of the laser discs available to us were too elementary for the college level. If this experiment were repeated with well-produced video clips, the results could well be very impressive.

A third, and obvious, conclusion is that our sample was too small. If we had carried out this experiment with 1,000 students, our results on all exams would have been significant at the .05 level assuming similar results.

Finally, the Hawthorn Effect could have been at work. If the students in the traditional sections discovered that an experiment was taking place, they could have studied harder, explaining the less than positive results on the second examination. We do not believe this to be the case, however. At the end of the course, we asked all students to let us know if there was something they did not like about the course, and we specifically asked if there was something about their section that they did not like. We received no indication that students were concerned that they were in the traditional class. While this is not proof that they did not know, it suggests that our findings are the result of some other factor.

Experiments such as this one should be continued. As educators, we must determine whether it is worthwhile to spend large portions of the education budget to purchase high-tech gadgetry. If multimedia equipment assists the learning process, then we should proceed in this direction with haste and enthusiasm. If, however, computers, laser discs, and the like do not assist us in educating today's students in measurable ways, then we should return to the chalkboard, both literally and figuratively, to find better ways to educate. Additionally, these types of experiments will be very useful in producing good video supplements in the classroom, if indeed we find that visual stimulus does enhance learning.

Perhaps the most important lesson that we learned from conducting this experiment is that the use of multimedia technology in the classroom is extraordinarily time consuming. Those who believe that education will be enhanced through the purchase of technology alone are not familiar with the attendant labor costs of such systems. There is a very likely danger that advanced technology costing hundreds of thousands of dollars will remain underused because educators do not have the training or cannot afford the time to use it to its full potential.

In sum, video segments had a small impact on our students' ability to understand and retain concepts of American government. This small attempt to collect data is certainly not the last word on the subject, but earlier pessimistic findings appear on the surface to have been at least tentatively substantiated.

\section{Notes}

*This paper was presented at the 1992 Annual Meeting of the American Political Science Association, Chicago, Illinois. 
1. Students are predominantly white males from middle-class families.

2. The main sources for these video clips were the $\mathrm{ABC}$ News interactive discs, Powers of the Congress, Powers of the President, and Powers of the Supreme Court; a preproduction video disc designed to accompany Ken Janda's American government text, The Challenge of Democracy, Houghton Mifflin Publisher; an American government disc marketed by Harper-Collins; and various VHS clips collected by members of the department over the years.

3. Statistically this creates a one-tail test for significance.

4. The fact that the students in the video sections performed no better on the nonvideo questions also suggests that there was no spillover effect or that the use of video would spur a generally higher performance on all questions.

5. In addition to two examinations and a final examination, there were two short papers.

\section{References}

Janda, Kenneth. 1992. "Multimedia in Political Science: Sobering Lessons from a Teaching Experiment." Journal of Educational Multimedia and Hypermedia $1: 341-54$.

Spencer, Ken. 1991. "Modes, Media, and Methods: The Search for Educational Effectiveness." British Journal of Educational Technology 22:12-22.

Summers, Jerry A. 1990-91. "Effect of Interactivity Upon Student Achievement, Completion Intervals, and Affective Perceptions." Journal of Educational Technology Systems 19:53-57.

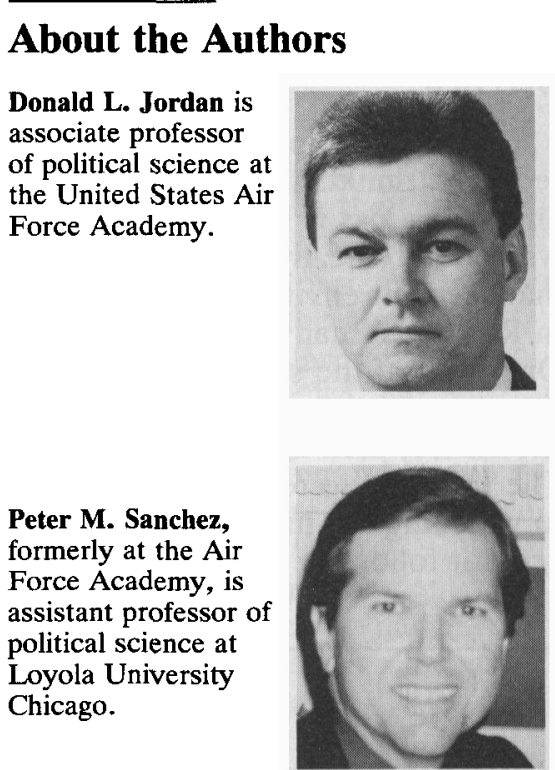

\title{
Teaching Public Administration by Exploiting Managerial Experience
}

\author{
Dorothy Olshfski, Rutgers University, Newark
}

Creating and transmitting knowledge to understand, analyze, and evaluate organizational problems is the major strength of university education in public administration. Undoubtedly, the cognitive aspects of management can be effectively transmitted in the classroom.

But understanding is one thing. Being able to perform is something entirely different (Ryles 1949). Just as swimming needs to be practiced in a pool in order to be mastered, the processes of managing need to be practiced in managerial situations, and cannot be taught through lecture alone (Mintzberg 1975).

Experience provides insight into ways a manager can accomplish tasks plus strategies for implementing ideas. In examining behavioral responses to managerial problems, Simon (1978) found that some managers have an extensive repertoire of experiences and solutions which they access more through recognition than a conscious systematic effort to recall experience. Similarly, Isenberg (1986) found that managers use analogical thinking to decide on actions to deal with organizational problems. And reasoning by analogy was described by Stone
(1988) in her model of policy analysis and by Waldrop (1992) in his description of the unfolding of the science of complexity. But in one of the few studies of what managers learn from experience, McCall, Lombardo, and Morrison (1988) found only that while different experiences provide different lessons, not all managers learned the same thing from the same situations.

But experience need not all be actual, on-the-job type of experience; it can be experience gained vicariously, i.e., secondhand. Gaining vicarious experience involves watching a person who effectively demonstrates a particular managerial behavior; analyzing the processes and behaviors used by the manager; and then attempting to model the behavior in the observer's own setting. As in most learning situations, feedback or thoughtful analysis of the effectiveness of the modeled behavior enhances the learning opportunity.

Vicarious experience can also be gained from studying history, biography, films, and analyzing managers' stories. For example, Neustadt and May (1986) advocate using historical analysis to examine the pro- cesses reportedly used by political decision makers in order to improve the decision-making skills of the observer.

Biography is also a source of vicarious experience. Doig and Hargrove (1987) and Cooper and Wright (1992) have gathered biographies of public sector leaders which can be analyzed according to the leader's strategies and behaviors. Even movies and novels, if experienced with an eye toward learning the why and how of a particular behavior, can be used to enhance managerial skills. In the classroom, the ordinary vehicle for conveying vicarious experience is the simulation or case study.

But the process of gaining and using vicarious experience to enhance mánagerial skills is an unexplored research area. This paper examines, first, the uses of experience in analyzing a management problem by practiced and novice managers. And secondly, the ease of transfer of vicarious experience is examined by presenting the participants with an experience and seeing if they can apply it to a similar case. 